\title{
ENDPOINT ESTIMATES FOR COMMUTATORS OF INTRINSIC SQUARE FUNCTIONS IN MORREY TYPE SPACES
}

\author{
HUA WANG
}

Abstract. In this paper, the boundedness properties of commutators generated by $b$ and intrinsic square functions in the endpoint case are discussed, where $b \in B M O\left(\mathbb{R}^{n}\right)$. We first establish the weighted weak $L \log L$-type estimates for these commutator operators. Furthermore, we will prove endpoint estimates of commutators generated by $B M O\left(\mathbb{R}^{n}\right)$ functions and intrinsic square functions in Morrey type spaces. In particular, we can obtain endpoint estimates of these commutators in the weighted Morrey spaces $L^{1, \kappa}(w)$ for $0<\kappa<1$ and $w \in A_{1}$, and in the generalized Morrey spaces $L^{1, \Theta}$, where $\Theta$ is a growth function on $(0,+\infty)$ satisfying the doubling condition.

Mathematics subject classification (2010): 42B25, 42B35.

Keywords and phrases: Intrinsic square functions, weighted Morrey spaces, generalized Morrey spaces, commutators, $A_{p}$ weights.

\section{REFERENCES}

[1] D. R. Adams, A note on Riesz potentials, Duke Math. J, 42 (1975), 765-778.

[2] J. Alvarez, R. J. BAgBy, D. S. Kurtz AND C. PÉReZ, Weighted estimates for commutators of linear operators, Studia Math, 104 (1993), 195-209.

[3] F. Chiarenza And M. Frasca, Morrey spaces and Hardy-Littlewood maximal function, Rend. Math. Appl, 7 (1987), 273-279.

[4] Y. Ding, S. Z. LU AND K. YABUTA, On commutators of Marcinkiewicz integrals with rough kernel, J. Math. Anal. Appl, 275 (2002), 60-68.

[5] J. DuonndikoetXea, Fourier Analysis, American Mathematical Society, Providence, Rhode Island, 2000.

[6] J. Garcia-Cuerva And J. L. Rubio de Francia, Weighted Norm Inequalities and Related Topics, North-Holland, Amsterdam, 1985.

[7] V. S. GuliYeV, Boundedness of the maximal, potential and singular operators in the generalized Morrey spaces, J. Inequal. Appl., Article ID 503948, (2009).

[8] V. S. Guliyev, S. S. Aliyev And T. Karaman, Boundedness of a class of sublinear operators and their commutators on generalized Morrey spaces, Abstr. Appl. Anal., Article ID 356041, (2011).

[9] V. S. Guliyev, S. S. Aliyev, T. Karaman and P. S. Shukurov, Boundedness of sublinear operators and commutators on generalized Morrey spaces, Integr. Equ. Oper. Theory, 71 (2011), 327 355.

[10] F. John And L. Nirenberg, On functions of bounded mean oscillation, Comm. Pure Appl. Math, 14(1961), 415-426.

[11] Y. KOMORI AND S. SHIRAI, Weighted Morrey spaces and a singular integral operator, Math. Nachr, 282 (2009), 219-231.

[12] S. Z. LU, D. C. YANG AND Z. S. ZHOU, Sublinear operators with rough kernel on generalized Morrey spaces, Hokkaido Math. J, 27 (1998), 219-232.

[13] T. Mizuhara, Boundedness of some classical operators on generalized Morrey spaces, Harmonic Analysis, ICM-90 Satellite Conference Proceedings, Springer-Verlag, Tokyo, (1991), 183-189.

[14] C. B. MorRey, On the solutions of quasi-linear elliptic partial differential equations, Trans. Amer. Math. Soc, 43 (1938), 126-166. 
[15] E. NAKAI, Hardy-Littlewood maximal operator, singular integral operators and Riesz potentials on generalized Morrey spaces, Math. Nachr., 166 (1994), 95-103.

[16] B. MucKenHouPT, Weighted norm inequalities for the Hardy maximal function, Trans. Amer. Math. Soc, 165 (1972), 207-226.

[17] J. PeEtre, On the theory of $\mathscr{L}_{p, \lambda}$ spaces, J. Funct. Anal, 4 (1969), 71-87.

[18] C. PÉREZ, Endpoint estimates for commutators of singular integral operators, J. Funct. Anal, 128 (1995), 163-185.

[19] C. PÉREZ ANd G. PRADOlini, Sharp weighted endpoint estimates for commutators of singular integrals, Michigan Math. J., 49 (2001), 23-37.

[20] C. PÉREZ AND R. TRUjILlo-GonZÁLEZ, Sharp weighted estimates for multilinear commutators, J. London Math. Soc., 65 (2002), 672-692.

[21] M. M. RaO AND Z. D. Ren, Theory of Orlicz Spaces, Marcel Dekker, New York, 1991.

[22] E. M. Stein, Singular Integrals and Differentiability Properties of Functions, Princeton Univ. Press, Princeton, New Jersey, 1970.

[23] H. WANG, Intrinsic square functions on the weighted Morrey spaces, J. Math. Anal. Appl, 396 (2012), 302-314.

[24] H. WANG, Weak type estimates for intrinsic square functions on weighted Morrey spaces, Anal. Theory Appl, 29 (2013), 104-119.

[25] H. WANG, Boundedness of intrinsic square functions on generalized Morrey spaces, Georgian Math. J, 21 (2014), 351-367.

[26] H. WANG, Boundedness of vector-valued intrinsic square functions in Morrey type spaces, J. Funct. Spaces., Article ID 923680, (2014), 8 pages.

[27] H. WANG, The boundedness of intrinsic square functions on the weighted Herz spaces, J. Funct. Spaces., Article ID 274521, (2014), 14 pages.

[28] M. Wilson, The intrinsic square function, Rev. Mat. Iberoamericana, 23 (2007), 771-791.

[29] M. WiLs ON, Weighted Littlewood-Paley Theory and Exponential-Square Integrability, Lecture Notes in Math, Vol 1924, Springer-Verlag, 2007.

[30] P. Zhang, Weighted endpoint estimates for commutators of Marcinkiewicz integrals, Acta Math. Sinica (Engl. Ser), 26 (2010), 1709-1722. 